\title{
Advanced Structure-Property Relationships: Made in Styria!
}

Which current challenges in materials research are being met in the Mur-Mürz region of Styria in 2015, where the tradition of iron forging can be traced back to times that precede Columbus' discovery of the Americas? In fact, the challenges around state-of-the-art metal forming are being met right here in Styria, and these remain a key topic for the production of high performance materials. Of course, modern thermo-mechanical processing has replaced the use of hammer forging. During the last decades, the areas of research at the Montanuniversität in Leoben have likewise been extended to advanced structure-property relationships across the entire production chain of materials. Moreover, several new classes of materials such as thin films or intermetallic alloys that complement the long-established tradition of steel research are being examined at multiple length scales through the application of advanced experimental techniques including new approaches to microscopy, mechanical testing, and microstructural modelling.

In this special issue of Berg- und Hüttenmännische Monatshefte, I showcase some of the exciting frontiers of materials research at the Montanuniversität Leoben. To underline the international focus of the materials science program in Leoben and to encourage our talented young researchers who have contributed to this issue, I have decided to publish their results in English.

Three articles cover the microstructural characterisation of steels. These include a heat-treatable steel alloyed with boron, a bainitic steel for the automotive industry, and austenite grain growth in a plain carbon steel. A correlative microscopy approach, combining scanning electron microscopy, transmission Kikuchi diffraction, and focused ion beam microscopy was applied in order to locate prior austenite grain boundaries in a $42 \mathrm{CrMo} 4$ steel for subsequent atom probe microscopy. In the plain carbon steel, austenite grain growth was studied in-situ via high-temperature-laser-scanning confocal microscopy.

I have included four articles on our leading non-ferrous materials research, including studies of an intermetallic $\beta$-stabilised $\gamma$-titanium-aluminide based alloy, a precipitation hardened molybdenum based alloy, functional molybdenum and titanium-nitride thin films, and on copper metallization as used in modern semiconductors. For example, a dilatometer setup was placed in a synchrotron X-ray beam to record structural changes during heating experiments in the titanium-aluminide alloy, and thermal cycling in thermo-mechanically fatigued copper films was studied via a combination of site-specific analyses using atomic force microscopy and electron backscatter diffraction.

I hope you enjoy my selection of articles on 'Advanced Structure-Property Relationships: Made in Styria!' in this special issue of Berg- und Hüttenmännische Monatshefte.

A friendly "Glück Auf" from the guest editor,

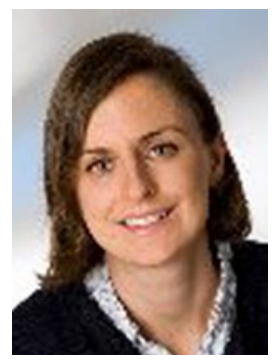

Sophie Primig

Montanuniversity Leoben,

Leoben, Austria

e-mail: sophie.primig@unileoben.ac.at 